\title{
Penile prosthesis surgery in out-patient setting: Effectiveness and costs in the "spending review" era
}

\author{
Nicola Mondaini ${ }^{1}$, Enrico Sarti ${ }^{1}$, Gianluca Giubilei ${ }^{2}$, Andrea Gavazzi ${ }^{3}$, Antonio Costanzi ${ }^{1}$, \\ Arben Belba ${ }^{3}$, Tommaso Cai ${ }^{4}$, Riccardo Bartoletti ${ }^{1}$ \\ ${ }^{1}$ Urology Unit, Santa Maria Annunziata Hospital (IOT), Florence, Italy; \\ ${ }^{2}$ Urology Unit, Leonardo Da Vinci Hospital, Empoli, Italy; \\ ${ }^{3}$ Urology Unit, CFO Oncology Center Florence, Italy; \\ ${ }^{4}$ Department of Urology, Santa Chiara Regional Hospital, Trento, Italy.
}

\begin{abstract}
Summary Introduction: Penile implant patients are required to remain in the hospital after the operation for monitoring, antibiotic and analgesia administration. Cost containment, however, has resulted in the increased use of ambulatory surgery settings for many surgical procedures. Few studies have studied the feasibility of performing penile prosthesis insertion in an outpatient setting. The results are controversial and nowadays, in the most of centers that deal with prosthetic surgery, patients are still hospitalized. Aim: The aim of our investigation was to compare the feasibility of the performance as well as the complication profiles of penile implant surgery performed in an in-patient and an outpatient setting at a single center by a single surgeon.

Methods: From January 2009 to June 2014, 50 patients of the same uro-andrological unit underwent penile prosthesis implantation performed by a single surgeon (N.M.). Twenty implantations were performed in an ambulatory day surgery setting.

Main outcome measures: Effectiveness and costs of outpatient setting versus the in-patient setting of the penile prosthesis surgery.

Results: There were some differences between the two groups in the intra-operative parameters, such as, operating time. Time lost from work was similar in both groups approximating 14 days. The mean number of analgesic pills ingested by the patients post-operatively was similar in both groups, averaging just under 25 pills per patient. There weren't post-operative complications in the outpatient group. Cost were $17 \%$ less in outpatient clinic.

Conclusions: The outpatient setting for this surgery is safe and effective even in patients with comorbidities or in case of secondary procedures. Costs are reduced by $17 \%$.
\end{abstract}

KeY WORDS: Penile prosthesis; Out-Patient; Erectile Dysfunction; Costs; Spending review.

Submitted 15 July 2014; Accepted 31 July 2014

\section{INTRODUCTION}

Inflatable penile prosthesis often represent the last or the only chance to get back to a normal life for patients with erectile dysfunction, reporting $70-87 \%$ satisfaction rates (1). Prosthesis can be either malleable or inflatable; the second one are preferred by most of patients but are much more expensive. At the moment, penile implant patients are required to remain in the hospital following the operation for monitoring, antibiotic and analgesia administration. Cost containment however, has resulted in the increased use of ambulatory surgery settings for many surgical procedures (2). Few studies have studied the feasibility of performing penile prosthesis insertion in an ambulatory setting (Table 1) (3-6). The results are controversial and nowadays, in the most of centers that deal with prosthetic surgery, patients are still hospitalized. The aim of our investigation was to compare the feasibility of performance as well as the complication profiles of penile implant surgery performed in an inpatient and an outpatient setting at a single center by a single surgeon.

\section{Materials AND METHODS}

From January 2009 to June 2014, 50 patients of the same uro-andrological unit underwent penile prosthesis implantation performed by a single surgeon (N.M.).

The first 30 were operated in an inpatient setting; the other 20 implantations were performed in an ambulatory day surgery setting. The day of the operation, all patients had intravenous antibiotics administrated: the inpatient group had teicoplanin $200 \mathrm{mg}$ and imipenem/cilastatin $500 \mathrm{mg} x$ 3 , while the out-patient group had amoxicillin/clavulanic acid 1 gr and gentamicin $80 \mathrm{mg} \times 2$. All procedures were performed through a transverse scrotal incision. The twopiece implant used was the Ambicorl device (AMS, Minneapolis, USA), while the three-piece implant used was the CX 700 device (AMS Minneapolis, USA). The indications for insertion of a two-piece rather than a three-piece device included a history of radical cystectomy, bilateral inguinal hernia surgery and patient choice. In both groups 
Table 1. Out-patient setting for penile prosthesis implantation in literature.

\begin{tabular}{|c|c|c|c|c|c|c|c|}
\hline \multirow[t]{2}{*}{ Author } & \multirow[t]{2}{*}{ Year } & \multirow[t]{2}{*}{ Out-patient } & \multirow[t]{2}{*}{ Age } & \multicolumn{2}{|c|}{ Prosthesis } & \multirow[t]{2}{*}{ Complications } & \multirow[t]{2}{*}{ Anesthesia } \\
\hline & & & & Two-Piece IPP & Three-Piece IPP & & \\
\hline Mondaini N. & 2014 & $\mathrm{n}=20$ & $64,2(53-74)$ & 10 AMS Ambicor & 10 AMS $700 \mathrm{CX}$ & 0 & Spinal \\
\hline Hsu GL. & 2004 & $n=10$ & $67.4 \pm 9.9$ & 7 AMS Ambicor & 3 AMS $700 \mathrm{CX}$ & na & $\begin{array}{l}\text { Crural nerve block - } \\
278 \text { mg } 0,8 \% \text { lidocaine sol. } \\
\text { and adrenaline }\end{array}$ \\
\hline Mulhall J. & 2001 & $n=46$ & $64 \pm 10$ & 9 AMS Ambicor & 37 Mentor Alpha-1 & $2(4,3 \%)$ & $\begin{array}{c}\text { Spinal/general } \\
\text { (laringeal mask) }+0,5 \% \\
\text { plain bupivacaine infiltrated } \\
\text { in the scrotal incision }\end{array}$ \\
\hline Garber BB. & 1997 & $n=95$ & 57 & 0 & 4 Mentor Alpha-1/AMS 700 & $6(6,3 \%)$ & General \\
\hline Lubensky JD. & 1991 & $n=74$ & $42-79$ & 0 & 74 AMS $700(100 \%)$ & $2(2,7 \%)$ & Spinal/general \\
\hline
\end{tabular}

the Foley catheter, which was placed intra-operatively, was removed the day after and a large scrotal compression dressing was placed (a scrotal support filled with fluffed gauze dressings) with also a large amount of ice, which was prescribed for the first 24 hours. The patients of the inpatient group where discharged after 1-3 days; while the patients of the outpatient group were discharged 3 hours after operation, on treatment with amoxicillin/clavulanic acid (1 gr PO twice daily for 10 days), gentamicin (80 mg IM twice daily for 10 days) and oral analgesics (paracetamol/codeine 1 pill every 4-6 hours). The patients treated in ambulatory setting were seen the day after and at 1-4 and 8 weeks post-operatively.

At the 4-week follow up visit, the patients were asked to count all analgesic pills taken, as well as the date of their return to work. On this date, they were also counseled regarding the proper utilization of their penile implant. Indeed, they were instructed to inflate and deflate the device daily for the next month. Costs were calculated using the actual price of antibiotics, hospital stay and

Table 2. Patient demographics.

\begin{tabular}{|lcc|}
\hline Age $(\mathrm{y})$ & $\begin{array}{c}\text { In-patient } \\
(n=30)\end{array}$ & $\begin{array}{c}\text { Out-patient } \\
(n=20)\end{array}$ \\
\hline Follow-up (months) & $63,3(22-78)$ & $64,2(53-74)$ \\
\hline Two-piece device & $56,5(36-77)$ & $12,1(1-24)$ \\
\hline Three-piece device & $5(16,6 \%)$ & $10(50 \%)$ \\
\hline Secondary procedures & $25(83,3 \%)$ & $10(50 \%)$ \\
\hline
\end{tabular}

penile prosthesis in our country. Statistical analysis between the groups was conducted using a Student's ttest (Excel, Microsoft Corp., USA).

\section{RESULTS}

There were not any demographic statistical differences in patient age, co-morbidity profile between the two groups of patients (Table 2). Follow-up was longer in the inpatient group. There were some differences between the two groups in the intra-operative parameters, such as, operating time (Table 3). Time lost from work was similar in both groups, approximating 14 days. The mean number of analgesic pills ingested by the patients post-operatively was similar in both groups, averaging just under 25 pills per patient (Table 3). There weren't post-operative complications in the outpatient group (Table 3). Cost were $17 \%$ less in outpatient setting (Table 4).

Table 3. Operative and post-operative data.

\begin{tabular}{|lcc|}
\hline $\begin{array}{c}\text { In-patient } \\
(n=30)\end{array}$ & $\begin{array}{c}\text { Out-patient } \\
(n=20)\end{array}$ \\
\hline $\begin{array}{l}\text { Intra-operative blood loss (mls) } \\
\text { OR time (min) } \\
\text { Two-piece device } \\
\text { Three-piece device }\end{array}$ & 100 & 80 \\
\hline Time lost from work (days) & 80 & 55 \\
\hline Narcotic use (pills) & 120 & 90 \\
\hline Overall complications & 25 & 13 \\
\hline Device infection & $2(6,6 \%)$ & 26 \\
\hline
\end{tabular}

\begin{tabular}{|lcc|}
\hline & $\begin{array}{c}\text { In-patient } \\
(1-3) \text { days }\end{array}$ & $\begin{array}{c}\text { Out-patient } \\
1 \text { day }\end{array}$ \\
\hline Hospital stay & $€ 800 \times 3=2400$ & $€ 800$ \\
\hline Intravenous antibiotics & $\begin{array}{l}\text { (Targosid) } 41,61 \times 3=124,83 \\
\text { (Tenacid) } € 23,97 \times 9=215,73\end{array}$ & $€ 3,75$ \\
\hline Cost & $€ 2.740,56$ & $€ 808,35$ \\
\hline Total cost & $€ 11.240$ & $€ 9.308,35$ \\
\hline${ }^{*}$ Cost are reduced by 17\%. & & \\
\hline
\end{tabular}

Table 4.

Cost difference between in-patient and out-patient settings for three-piece-device. 


\section{Discussion}

When available, outpatient surgery is well tolerated and often preferred by patients and in the past decade various studies were conducted about cost containment and safety of the management in outpatient setting in an increasing number of different surgery procedures (711). Nowdays, in Italy, the total cost for an implantation of an inflatable prosthesis is about $€$ 9000-15000, depending on conventions between hospitals and the local administrations. The cost includes pre-operative examinations, imaging, prosthesis, surgeon, anesthesiologist, hospital stay and medications. For this reason, living in a period of spending review involving all the western countries, the cost of this surgery restricted to 500 the total operations made annually in Italy. Our data demonstrate that in terms of safety and effectiveness the ambulatory setting is absolutely similar to the inpatient setting, reducing days of hospitalization (1-3) and using less expensive antibiotics (Table 4). This results in an overall saving of $17 \%$. Previous studies (9-13) about the feasibility of implantation of inflatable penile prosthesis in ambulatory settings showed complications rate of 1.8$6 \%$. To our knowledge only Mulhall (9) in 2001 compared performance and complications of inpatient and outpatients groups with penile prosthesis insertion. Overall complication rates were $6 \%$ for the inpatient group and $4 \%$ for the outpatient group, infection rate was 3\% for the first group and 2\% for the second. Our data confirm Mulhall study strengthening it, as our outpatient complications and infection rates are $0 \%$. The main study limitation is the small sample size, but emphasizes that surgeon's experience and a tight followup are essential in order to perform this procedure in an ambulatory setting, discharging the patient a few hours after surgery. It's also important underline that complications rate are now lower thanks to the evolution of prosthetic materials (12), which today are covered by antibiotic substances and discharging the patient with catheter and prosthesis inflated reduce the risk of postoperative hematoma, which often leads to infection. About the post-operative use of analgesics our data are similar to the literature.

\section{Conclusion}

The outpatient setting for this surgery is safe and effective even in patients with comorbidities or in case of secondary procedures. Costs are reduced by $17 \%$.

\section{ACKNOWLEDGMENTS}

We thank the team of anesthesia of the day service IOT Hospital, Florence: Antonella Orvieto, Anna Mancini, Elena Gandini, Eleonora Gentili, Eleni Kastamoniti, Anna Cianciullo, Vanna Viviani.

\section{References}

1. Parsons KF, Fall M, Irani J, Llorente C. Guidelines on male sexual dysfunction: erectile dysfunction and premature ejaculation. [Internet]. European Urology. 2013. Available from: http://www.uroweb.org/guidelines/online-guidelines/
2. Hollingsworth JM1, Saigal CS, Lai JC, et al. Medicare payments for outpatient urological surgery by location of care. J Urol. 2012; 188:2323-7.

3. Hsu G-L, Hsieh C-H, Wen H-S, et al. Outpatient penile implantation with the patient under a novel method of crural block. Int $J$ Androl. 2004; 27:147-51.

4. Mulhall JP, Bloom K. Comparison of in-patient and out-patient penile prosthesis surgery. Int J Impot Res. 2001; 13:251-4.

5. Garber BB. Outpatient inflatable penile prosthesis insertion. Urology. 1997; 49:600-3.

6. Lubensky JD. Outpatient Inflatable Penile Prosthesis. J Urol. 1991; 145:1176-7.

7. Krummenauer F, Günther K-P, Witzlebf W-C. The incremental cost effectiveness of in-patient versus out-patient rehabilitation after total hip arthroplasty - results of a pilot investigation. Eur J Med Res. 2008; 13:267-74.

8. Pineault R, Contandriopoulos AP, Valois M, et al. Randomized clinical trial of one-day surgery. Patient satisfaction, clinical outcomes, and costs. Med Care. 1985; 23:171-82.

9. Morgan M, Beech R. Variations in lengths of stay and rates of day case surgery: implications for the efficiency of surgical management. J Epidemiol Community Health. 1990; 44:90-105.

10. Roos NP. What is the potential for moving adult surgery to the ambulatory setting? CMAJ. 1988; 138:809-16.

11. Weale a R. Randomized clinical trial of the effectiveness of emergency day surgery against standard inpatient treatment (Br J Surg. 2002; 89:423-7). Brit J Surg 2002; 89:1323.

12. Muench PJ. Infections versus penile implants: the war on bugs. $J$ Urol. 2013; 189:1631-7.

\author{
Correspondence \\ Nicola Mondaini, MD \\ info@nicolamondaini.it \\ Enrico Sarti, MD \\ Antonio Costanzi, MD \\ Riccardo Bartoletti, MD \\ Urology Unit, Santa Maria Annunziata Hospital (IOT), Florence, Italy \\ Gianluca Giubilei, MD \\ Urology Unit, Leonardo Da Vinci Hospital, Empoli, Italy \\ Andrea Gavazzi, MD \\ Arben Belba, MD \\ Urology Unit, CFO Oncology Center Florencen, Italy \\ Tommaso Cai, MD
}

Department of Urology, Santa Chiara Regional Hospital, Trento, Italy 